\title{
Phonemes of Xi'an Dialect and Statistic Study of Phonemic Combination Frequency
}

\author{
Yonghong $\mathrm{Li}^{\mathrm{a}}$, Han $\mathrm{Wu}^{\mathrm{b}}$ \\ Key Lab of China's National Linguistic Information Technology, Northwest University for Nationalities, \\ Lanzhou, Gansu 730000, China; \\ alyhweiwei@126.com, bwu2006han@126.com
}

Keywords: Phoneme; Xi'an; dialect, frequency

\begin{abstract}
By using 3000 semantic units of Xi'an dialect from Characters Collection of Chinese Dialects as original database, the article calculates the frequency of initials, finals and tones, and also conducts a frequency statistic of the combination types of initials, finals and tones. Based on this study, the article probes into the syllable distribution, syllabic combination and the role of rhyme, offers a quantitative analysis of function of each phoneme and their combination capacity so as to provide fundamental data for the further study of phonemic theory study of Xi'an dialect.
\end{abstract}

\section{Introduction}

Phonemes are the smallest speech units to differentiate the semantic meanings in linguistic system. The number and type of phonemes vary from language to language. In Chinese-Tibetan languages, the syllabic form are all single characters with a single sound. The three major elements of speech system are initials, finals and tones. In these languages, some have more than 100 phonemes, some have about 20 - 30 phonemes. All these phonemes are very different from each other in terms of frequency, function and roles. Xi'an dialect belongs to Guanzhong dialect of Shaanxi, is the representative of Dongfu dialect of Guanzhong and that of Shaanxi dialect. Xi'an dialect is also one of the representative dialects in northwest China. The previous studies concerning phonemes of Xi'an dialect are mainly focusing on summary, differences and evolution of these phonemes [1, 2]. There are few studies of phonemes frequency and their functions. There are some statistical analysis of some phonemes concerning Chinese Putonghua, Beijing dialect and sporadic analysis of ethnic languages [3, 4]. The original database of this very study is Characters Collection of Chinese Dialects edited by the department of Chinese languages and literature and the division of language teaching of Beijing University [5]. The article calculate the frequency of initials, finals and tones of Xi'an dialect, and conducts a frequency statistic of the combination types of these initials, finals and tones so as to probe into the issues concerning its syllable distribution, types of syllable combination and the role of rhymes and tones.

\section{Homographs Statistics}

All the 3000 characters in Xi' an dialect correspond with 1016 syllables, and on average each syllable has 2.95 honographs. The syllables with most homographs are as follows: [ta21] (21 homographs), [6i21] (16), [t6i55] (15) and [\$y55] (15). 331 syllables have just one corresponding characters and not homongraphs, and they cover $11.03 \%$ of all syllable tyeps. 238 syllables have just two homographs and are $7.9 \%$ of all syllable types. The homongraph numbers of all the syllables are shown in figure 1. 


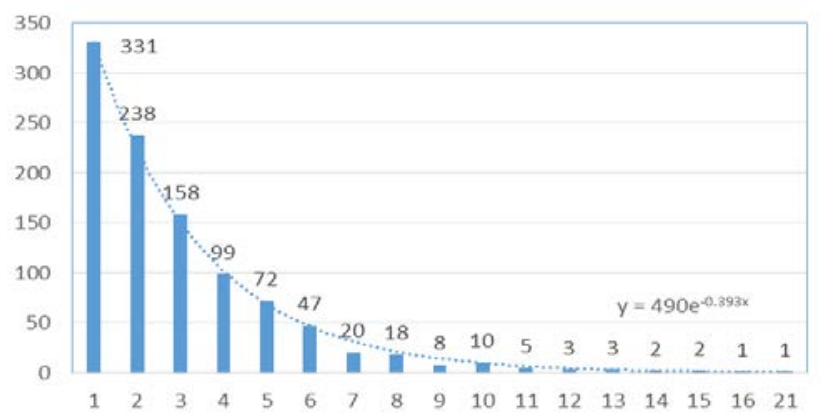

Fig. 1 Homograph Numbers of the Syllalbes in Xi'an Dialect

\section{Frequency Statistics of Phonemic System}

\subsection{Frequency Statistics of Initials.}

There are 27 initials in Xi' an dialect. Compared with Beijing dialect, there are more labial-dental affricates and fricatives, and many nasals in the initials of Xi'an dialect. The statistic results are as follows in table 1.

Table 1 Frequency of Initials in Xi'an Dialect

\begin{tabular}{cccccccccccc}
\hline No. & Init. & Freq. & No. & Init. & Freq. & No. & Init. & Freq. & No. & Init. & Freq. \\
\hline 1 & $\$$ & 313 & 8 & t $^{\mathrm{h}}$ & 133 & 15 & $\mathrm{p}^{\mathrm{h}}$ & 101 & 22 & $\mathrm{v}$ & 42 \\
2 & $\mathrm{t}$ & 237 & 9 & $\mathrm{k}$ & 133 & 16 & $\mathrm{ts}^{\mathrm{h}}$ & 98 & 23 & $\mathrm{pf}^{\mathrm{h}}$ & 38 \\
3 & 6 & 186 & 10 & $\mathrm{f}$ & 132 & 17 & $\mathrm{ts}$ & 94 & 24 & $\mathrm{y}$ & 32 \\
4 & $\mathrm{l}$ & 186 & 11 & $\mathrm{ts}$ & 131 & 18 & $\mathrm{k}^{\mathrm{h}}$ & 80 & 25 & $\mathrm{\eta}$ & 31 \\
5 & $\mathrm{X}$ & 148 & 12 & $\mathrm{t}^{\mathrm{h}}$ & 129 & 19 & $\mathrm{~s}$ & 77 & 26 & $\mathrm{n}$ & 28 \\
6 & $\mathrm{t}$ & 143 & 13 & $\mathrm{~s}$ & 128 & 20 & $\mathrm{pf}$ & 53 & 27 & $\mathrm{z}$ & 22 \\
7 & $\mathrm{p}$ & 137 & 14 & $\mathrm{~m}$ & 114 & 21 & $\mathrm{te}^{\mathrm{h}}$ & 54 & & & \\
\hline
\end{tabular}

In terms of speech organs, laminal (anterior) phonemes have higher frequency, is $19.5 \%$ of all phonemes, and mid-apical ones are only $8.3 \%$. In terms of speech manners, the most frequent ones are affricates and are $27.9 \%$ of all phonemes, and least frequent ones are laterals (only 6.2\%) and nasals are $6.8 \%$. Besides zero initial, the most frequent initial is[t6] (7.9\%). The least frequent initial is [z ] $(0.77 \%)$.

\subsection{Frequency Statistics of Finals.}

There are 40 finals in Xi'an dialect. Finals of single vowel and finals of compound vowels are 1.3 and 1.4 times of those in Beijing dialect. However, the finals with nasal ending are less than half of those in Beijing dialect. The statistic results are as is in table 2.

Table 2 Frequency of Finals in Xi' an dialect

\begin{tabular}{|c|c|c|c|c|c|c|c|c|c|c|c|}
\hline No. & Final & Freq. & No. & Final & Freq. & No. & Final & Freq. & No. & Final & Freq- \\
\hline 1 & $\mathrm{i}$ & 253 & 11 & iau & 94 & 21 & $1^{3}$ & 72 & 31 & yon & 23 \\
\hline 2 & $\mathrm{u}$ & 199 & 12 & uei & 93 & 22 & ian & 68 & 32 & uay & 23 \\
\hline 3 & $\tilde{\mathfrak{z}}$ & 189 & 13 & uo & 91 & 23 & iou & 59 & 33 & yẽ & 21 \\
\hline 4 & i & 151 & 14 & ei & 87 & 24 & ũ̃ & 57 & 34 & yo & 19 \\
\hline 5 & ay & 130 & 15 & uor & 86 & 25 & $\mathrm{Y}$ & 46 & 35 & ua & 19 \\
\hline 6 & $\mathrm{au}$ & 126 & 16 & $\tilde{\mathrm{e}}$ & 86 & 26 & $\vartheta$ & 45 & 36 & $u æ$ & 13 \\
\hline 7 & әn & 125 & 17 & $\mathfrak{x}$ & 84 & 27 & 0 & 43 & 37 & ye & 12 \\
\hline 8 & ou & 124 & 18 & ie & 75 & 28 & uẽ & 40 & 38 & $\mathrm{i} \mathfrak{z}$ & 8 \\
\hline 9 & in & 116 & 19 & iẽ & 73 & 29 & ia & 38 & 39 & $\partial$ & 5 \\
\hline 10 & $\mathrm{y}$ & 96 & 20 & $a$ & 73 & 30 & у & 38 & P & T & 9 \\
\hline
\end{tabular}

In Xi'an dialect, the finals with nasal ending are mainly[y] and there are not any finals ended with [m] or [n]. There are 20 finals of compound vowels, and they correspond with 1237 characters (41.2\% of all types). 12 finals with single vowel correspond with 1192 characters and covers 39.7\% of all types. There are only 7 finals ended with nasal, the least frequent final, and cover only $19 \%$. 


\subsection{Frequency Statistics of Tone.}

The frequency statistics has been conducted in terms of the 4 tones in $\mathrm{Xi}$ 'an dialect. The most frequent one is 24 , the least frequent one is tone 4 , and 21 and 53 come between them. The results are as in tahle 3 .

Table 3 Frequency Statistics of Tones in Xi'an Dialect

\begin{tabular}{|c|c|c|c|c|c|c|}
\hline Tone Type & Ring Marking & Vertical Marking & Tone Value & Freq. & Percentage (\%) & Example \\
\hline Tone I & דים & $\mathrm{J}$ & 21 & 962 & 29.5 & gao \\
\hline Tone II & דים & 1 & 24 & 684 & 23.8 & ping \\
\hline Tone III & ים & $y$ & 53 & 536 & 19.9 & ding \\
\hline Tone IV & $a^{2}$ & 1 & 55 & 818 & 26.9 & jiao \\
\hline
\end{tabular}

\section{Frequency Statistics of Phonemic Combination}

The article has studied the combination relationship of all the 3000 syllables in Xi'an dialect. The value of frequency of these combinations shows the stability of the combinations. The higher the frequency is the higher level the syllabic structures have. The article has also conducted the calculation and analysis of the frequency of the combination of initial-final, initial-tone and final-tone.

\subsection{Frequency Statistics of Initial-Final Combination.}

In Xi'an dialect, the 27 initials and 39 finals can have 375 combinations. The most frequent combination is [fu], and it appears in 46 characters; the number of the least frequent combination is 28 and they only appear one character. The first 20 initial-final combinations are as in table 4 .

Table 4 Frequency of Initial-Final Combination in Xi'an Dialect

\begin{tabular}{|c|c|c|c|c|c|c|c|}
\hline No. & Comb. & Freq. & Percentage (\%) & No. & Comb. & Freq. & Percentage (\%) \\
\hline 1 & $f u$ & 46 & 1.53 & 11 & ts) & 24 & 0.80 \\
\hline 2 & tci & 44 & 1.47 & 12 & pi & 23 & 0.77 \\
\hline 3 & sl & 37 & 1.23 & 13 & $6 y$ & 22 & 0.73 \\
\hline 4 & $\$ \mathrm{i}$ & 33 & 1.10 & 14 & xuei & 22 & 0.73 \\
\hline 5 & teģ $\sigma$ & 32 & 1.07 & 15 & $6 g \widehat{C} \sigma$ & 22 & 0.73 \\
\hline 6 & $\$ y$ & 32 & 1.07 & 16 & ts? & 21 & 0.70 \\
\hline 7 & $t^{\mathrm{h}} \mathbf{i}$ & 30 & 1.00 & 17 & tciau & 21 & 0.70 \\
\hline 8 & li & 30 & 1.00 & 18 & tcie & 21 & 0.70 \\
\hline 9 & "ģఠ $\sigma$ & 28 & 0.93 & 19 & \$uei & 21 & 0.70 \\
\hline 10 & 6i & 24 & 0.80 & 20 & $t 6^{h} \mathrm{gC} \sigma$ & 20 & 0.67 \\
\hline
\end{tabular}

\subsection{Frequency Statistics of Initial-Tone Combination.}

In Xi'an dialect, the 27 initials and 4 tones can have 108 combinations. These types of combination are complete, and all initials can go with all 4 tones. The most frequent combination is [t621]; the least frequent combinations are [k24] and [pf24], and they only appear one character. The first 20 initial-tone combinations are as in table 5.

Table 5 Frequency of Initial-Tone Combination in Xi'an Dialect

\begin{tabular}{cccccccc}
\hline No. & Comb. & Freq. & Percentage $(\%)$ & No. & Comb. & Freq. & Percentage (\%) \\
\hline 1 & $\mathrm{tc}(21)$ & 95 & 3.17 & 11 & $\mathrm{~s}(21)$ & 59 & 1.97 \\
2 & $\$(24)$ & 92 & 3.07 & 12 & $\mathrm{x}(24)$ & 57 & 1.90 \\
3 & $\$(21)$ & 91 & 3.03 & 13 & $\mathrm{t}(24)$ & 55 & 1.83 \\
4 & $\mathrm{t}(55)$ & 88 & 2.93 & 14 & $\mathrm{p}(55)$ & 54 & 1.80 \\
5 & $\$(55)$ & 81 & 2.70 & 15 & $6(55)$ & 51 & 1.70 \\
6 & $\mathrm{l}(24)$ & 79 & 2.63 & 16 & $\mathrm{p}(21)$ & 51 & 1.70 \\
7 & $6(21)$ & 77 & 2.57 & 17 & $\$(53)$ & 49 & 1.63 \\
8 & $\mathrm{t}(55)$ & 69 & 2.30 & 18 & $\mathrm{ts}(21)$ & 48 & 1.60 \\
9 & $\mathrm{k}(21)$ & 66 & 2.20 & 19 & $\mathrm{x}(55)$ & 47 & 1.57 \\
10 & $\mathrm{tc}^{\mathrm{h}}(21)$ & 60 & 2.00 & 20 & $\mathrm{~m}(24)$ & 43 & 1.43 \\
\hline
\end{tabular}




\subsection{Frequency Statistics of Final-Tone Combination.}

In Xi'an dialect, the 39 finals and 4 tones can have 150 combinations. In all possi` jc dg _j-rnd c ank `g_rghl q*rf cpc_pc nl jw 4 runcq molank `g_rghl qbml m_nnc_pg rf c 1. . . qwj_`jcq*_lb rf cw

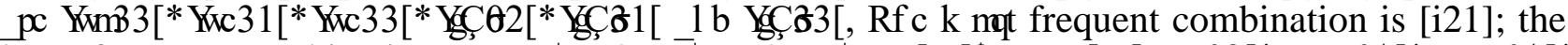

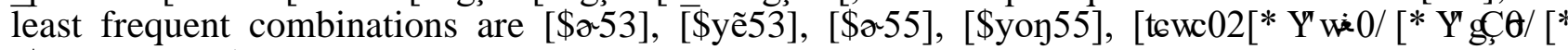
[\$o24] and [t ${ }^{\mathrm{h}}$ yo53] and they only appear one character. The first 20 final-tone combinations are as in table 6.

Table 6 Frequency of Final -Tone Combination in Xi'an Dialect

\begin{tabular}{|c|c|c|c|c|c|c|c|}
\hline No. & Comb. & Freq. & Percentage (\%) & No. & Comb. & Freq. & Percentage (\%) \\
\hline 1 & $\mathrm{i}(21)$ & 89 & 2.97 & 11 & uei(55) & 45 & 1.50 \\
\hline 2 & i(55) & 73 & 2.43 & 12 & әท(21) & 46 & 1.53 \\
\hline 3 & Ç(55) & 62 & 2.07 & 13 & әฤ(24) & 41 & 1.37 \\
\hline 4 & $\mathrm{u}(55)$ & 58 & 1.93 & 14 & Ç(553) & 39 & 1.30 \\
\hline 5 & $\mathrm{i}(24)$ & 57 & 1.90 & 15 & $\mathrm{au}(55)$ & 39 & 1.30 \\
\hline 6 & $u(53)$ & 51 & 1.70 & 16 & $\mathrm{uo}(21)$ & 39 & 1.30 \\
\hline 7 & $\mathrm{u}(21)$ & 52 & 1.73 & 17 & $\mathrm{u}(24)$ & 38 & 1.27 \\
\hline 8 & @્f(55) & 50 & 1.67 & 18 & $g(-24)$ & 37 & 1.23 \\
\hline 9 & Ç(-21) & 51 & 1.70 & 19 & $C ̧(224)$ & 37 & 1.23 \\
\hline 10 & ei(21) & 48 & 1.60 & 20 & $\operatorname{ie}(21)$ & 37 & 1.23 \\
\hline
\end{tabular}

\section{Summary}

The article has conducted a frequency statistics of phonemes and phonemic combinations in Xi'an dialect. We have also ordered the phonemes and phonemic combinations in language system, and studied the function of phonemes in a quantitative way. The phonemic system of Chinese-Tibetan languages consists of initials, finals and tones, we can apply the same method to the calculation to other languages of Chinese-Tibetan language family. Thus, we can synchronically compare different dialects, and diachronically conduct quantitative study of the evolution of phonemic system.

\section{Acknowledgements}

This article is subsidized by special Projects of Northwest University for Nationalities (31920160002).

\section{References:}

[1] Yao Meirong, On Changes of Speech of Xi'an Dialect -- Comparison of Articulation of Old and New Xi'an Dialect ,Master Thesis of Shaanxi Normal University, 2014

[2] Guo Yongliang, On Differences of Initials and Finals in Xi'an Dialect, Master Thesis of Northwest University, 2010

[3] Li Yonghong, Fang Huaping. Distribution of the Phonetic System and Statistical Studies for Beijing Dialect, 2011 International Conference on Social Sciences and Society. (2011) 247-253.

[4]. Su Xinchun, Lin Jinzhan, Statistic Analysis of Syllables and Character-Load Function of Chinese Putonghua --- Based on the Contemporary Chinese Dictionary, Chinese Languages.3(2006) 274-284.

[5]. the department of Chinese languages and literature and the division of language teaching of Beijing University, Characters Collection of Chinese Dialects, second ed., Languages Press, China, 2003. 